\title{
Development and characterisation of 16 novel microsatellite markers for the brown alga Sargassum fusiforme (Harvey) Setchell
}

\author{
QIAOCHU YOU ${ }^{1,2}$, YURONG ZHANG ${ }^{2}$, WANGDONG FU ${ }^{3}, \mathrm{CHANGFENG} \mathrm{CHI}^{1,2}, \mathrm{TIEJUN} \mathrm{LI}^{2}$ \\ AND YUANMING GUO ${ }^{2}$ \\ ${ }^{1}$ National Engineering Research Centre of Marine Facilities Aquaculture, School of Marine Science and Technology \\ Zhejiang Ocean University, Zhoushan - 316 022, PR China \\ ${ }^{2}$ Marine Fishery Institute of Zhejiang Province, Key Lab of Mariculture and Enhancement of Zhejiang province - 316100 \\ Zhoushan, Zhejiang Province, PR China \\ ${ }^{3}$ Zhejiang Marine Development Research Institute, Zhoushan, Zhejiang Province - 316 021, PR China \\ e-mail: yurongzhang2008@163.com
}

\begin{abstract}
Sargassum fusiforme (Harvey) Setchell (Sargassaceae, Phaeophyta) is an ecologically and economically important kelp species in East Asia. Restoration and responsible utilisation of $S$. fusiforme would be facilitated by the availability of an appropriate set of molecular markers. In the present study, we developed 16 microsatellite markers for S. fusiforme. A total of 99 different alleles were observed at the 16 microsatellite loci across 50 individual samples. The number of alleles per locus ranged from 4 to 10 , with an average of 6.2 per locus. The observed and expected heterozygosities ranged from 0.483 to 0.833 and from 0.513 to 0.840 , respectively. Only three of the loci deviated significantly from Hardy-Weinberg equilibrium after Bonferroni correction. No significant linkage disequilibrium was detected among the microsatellite loci. The obtained microsatellite markers will facilitate related research on $S$. fusiforme, such as ecological studies and genetic diversity assessments.
\end{abstract}

Keywords: Genetic diversity, Microsatellite, Polymorphism, Sargassum fusiforme

The large brown alga Sargassum fusiforme (Harvey) Setchell is widely distributed in the lower intertidal zones of the western North Pacific and is commercially cultivated as a food-stuff in South Korea, Japan and China (Hwang et al., 1994; Sun et al., 1996). This alga has important ecological functions both as a substantial contributor to marine primary production and as a seaweed bed habitat for spawning, nurseries and feeding of nearshore benthic marine organisms. However, the market demand for this alga is increasing because of its high commercial value in the nutrition and pharmaceutical industries (Pang et al., 2005; Choi et al., 2009). S. fusiforme is intensively cultivated in China and aquaculture of this alga has become a well developed industry in Zhejiang and Fujian provinces (Pang et al., 2005; 2006). However, over the last decade, natural resources of $S$. fusiforme have been severely damaged by overexploitation and ocean pollution. Along the coast of Zhejiang Province in the East China Sea, the floating biomass of S. fusiforme, which was once distributed widely in near-shore waters and the waters around islands, has been disappearing steadily since the end of the 1990s (Sun et al., 1996). Artificial breeding and seeding have also caused a serious decline in natural
S. fusiforme biomass, even resulting in the "Isoyake" phenomenon (Pang et al., 2005; Yu et al., 2012). Therefore, the restoration and sustainable exploration of natural resources of $S$. fusiforme are of critical importance.

Molecular markers are important tools for population genetic studies, which could enhance the responsible exploitation of Sargassum species. In S. fusiforme, a variety of marker systems have been used for genetic analyses, including RAPD, ISSR, SCAP and AFLP (Park et al., 1998; Yu et al., 2012; Nan et al., 2015). However, although microsatellite markers are superior to the aforementioned markers for genetic analyses because of their high mutation rate and co-dominant Mendelian inheritance, no genomic microsatellite markers are available for $S$. fusiforme. In the present study, we developed and characterised 16 microsatellite markers for S. fusiforme. These new markers will facilitate future studies on the genetic diversity and structure of $S$. fusiforme populations and aid in the breeding programmes.

S. fusiforme was collected from lower intertidal rocks along the coastline of Dongtou, Zhejiang Province $(120.80 \mathrm{E}, 27.85 \mathrm{~N})$. Sporophytes of S. fusiforme, 
approximately $10 \mathrm{~m}$ apart, were randomly collected. Fifty individuals were randomly sampled and 2-3 lateral branches from each individual were collected and preserved at $-80^{\circ} \mathrm{C}$ until use. Genomic DNA was extracted from the leaves of $S$. fusiforme by the modified cetyltrimethylammonium bromide (CTAB) method described by Shan and Pang (2009).

Microsatellite loci were isolated and cloned according to the protocol described by Yue et al. (2000). A partial genomic DNA library enriched for CA-repeats was constructed using an enrichment technique. DNA was digested with $R s a \mathrm{I}$ and the resulting fragments were separated on a 1\% agarose gel. Fragments sized 250-1000 bp were excised, purified and ligated to 21- and 25-mer oligo adaptors (20 pmol) (Fischer and Bachmann, 1998). CA-repeats in the ligated DNA were enriched using biotinylated probes $(\mathrm{CA})_{10}$ and streptavidin-coated magnetic beads (Dynal) and then the DNA containing microsatellites captured by the magnetic beads was eluted. The eluted fragments were amplified using 21mers as primers and then ligated into the pGEM-T-vector (Promega) according to the manufacturer's protocol. The generated plasmids were transformed into Escherichia coli XL-blue 1 competent cells (Stratagene). DNA from the obtained colonies was sequenced in $5^{\prime}$ and $3^{\prime}$ directions with an ABI3100 sequencer (Applied Biosystems, Foster City, CA, USA) using BigDye chemistry (Applied Biosystems). Primers were designed for 16 microsatellites in the regions flanking the repeats using Primer 3.0 software (Rozen and Skaletsky, 2000).

PCR amplification was conducted in a $25 \mu 1$ reaction mixture containing $10 \mathrm{pmol}$ of each primer set, $100 \mu \mathrm{mol} \mathrm{l}^{-1}$ dNTPs, $10 \mathrm{mmol} \mathrm{l}^{-1}$ Tris- $\mathrm{HCl}\left(\mathrm{pH} \mathrm{8.3),} 50 \mathrm{mmol} \mathrm{l}^{-1} \mathrm{KCl}\right.$, $1.5 \mathrm{mmol} \mathrm{l}^{-1} \mathrm{MgCl}_{2}, 1 \mathrm{U}$ of Taq polymerase (Takara Biotechnology, Dalian, China) and approximately $40 \mathrm{ng}$ of template DNA. The PCR profile consisted of an initial denaturation step at $94^{\circ} \mathrm{C}$ for $5 \mathrm{~min}$, followed by 30 cycles of $94^{\circ} \mathrm{C}$ for $30 \mathrm{~s}$, annealing for $45 \mathrm{~s}$ and $72^{\circ} \mathrm{C}$ for $1 \mathrm{~min}$ and a final elongation step at $72^{\circ} \mathrm{C}$ for $7 \mathrm{~min}$. Amplification products were separated on a $6 \%$ denaturing polyacrylamide gel and visualised by silver staining to screen out polymorphic microsatellites for further genetic analyses. After optimisation, one primer of each pair used for the genetic analyses was labeled with a fluorescent dye (FAM, NED, PET or VIC) and the PCR amplification was conducted as described above. Following amplification, the PCR products were mixed with $5 \mu$ of formamide HiDi and LIZ-500 size standard and heated at $95^{\circ} \mathrm{C}$ for $5 \mathrm{~min}$. The fluorescently labeled microsatellite PCR products were analysed on an $\mathrm{ABI} 3130 x \mathrm{x}$ DNA sequencer using GeneMapper 3.5 software (Applied Biosystems). The sizes of the PCR products were determined by comparison with the LIZ-500 size standard. Genotype data were exported as Microsoft Excel files for further analysis.

The number of alleles per locus $\left(N_{\mathrm{a}}\right)$, effective number of alleles $\left(N_{\mathrm{e}}\right)$, expected heterozygosity $\left(H_{\mathrm{e}}\right)$ and observed heterozygosity $\left(H_{\mathrm{o}}\right)$ were calculated using GenALEx 6 (Peakall and Smouse, 2006). Exact tests for Hardy-Weinberg equilibrium (HWE) of each sample for each locus and linkage disequilibrium (LD) between pairwise loci were tested by a Markov chain method (dememorisation $=10,000$, batches $=1000$ and iterations per batch $=10,000)$ using GENEPOP 4.0 (Rousset, 2008). The sequential Bonferroni technique was used to correct $p$ values for multiple tests (Rice, 1989).

Based on the sequences of the microsatellite repeats, 50 putative loci were randomly selected for screening and primers were ordered for these microsatellites. In the first round of screening, denaturing PAGE showed that 25 of the 50 primer sets successfully amplified microsatellite DNA from $S$. fusiforme. Of these 25 microsatellites, 16 polymorphic microsatellites were selected and primers labeled with fluorescent dye were ordered to avoid invalid microsatellites. The allele size was 180-392 bp (Table 1). One wild S. fusiforme population containing 50 individuals was used to analyse the polymorphism of the 16 screened primer pairs. For each of the 16 loci, $45-50$ of the S. fusiforme samples were successfully genotyped. A total of 99 different alleles were observed at the 16 microsatellite loci. The total number of alleles per locus in the tested population ranged from 4 to 10 (Table 1 ). The observed and expected heterozygosities ranged from 0.483 to 0.833 and 0.513 to 0.840 respectively. The number of alleles at each locus was similar to or higher than that at characterised microsatellite loci in other kelp species, such as Laminaria digitata (Liu et al., 2012), Gracilaria tenuistipitata (Song et al., 2014) and Gambierdiscus caribbaeus (Sassenhagen and Erdner, 2017).

The observed genotypic frequencies were tested for Hardy-Weinberg equilibrium. Only three of the loci (HM05, HM10, HM15) displayed heterozygosity levels that significantly deviated from HWE expectations after Bonferroni correction. No evidence of linkage disequilibrium (LD) was observed in the LD test for all pairs of loci in the population.

In summary, we report here 16 microsatellite loci as the first set of molecular markers developed for S. fusiforme. These newly developed microsatellite markers will facilitate range-wide studies on the genetic diversity and structure of $S$. fusiforme populations and will be useful for effective recovery and management planning towards population augmentation and cultivation. 
Table 1. Characteristics of 16 microsatellite markers developed for Sargassum fusiforme

\begin{tabular}{|c|c|c|c|c|c|c|c|c|c|c|}
\hline Locus & Repeat motif & Primer sequence 5'-3'(label) & $T_{\mathrm{a}}\left({ }^{0} \mathrm{C}\right)$ & Allele-size range & $\mathrm{N}$ & $\mathrm{Na}$ & Ho & $\mathrm{He}$ & $P_{\mathrm{HW}}$ & $\begin{array}{l}\text { Gen Bank } \\
\text { Acc. No. }\end{array}$ \\
\hline HM01 & $(\mathrm{TG})_{10}$ & $\begin{array}{l}\text { F:CTTGGTTTTAGGTATCCAGGCTCT } \\
\text { R:TGCCCACTCACCTGTGTCATT }\end{array}$ & 55 & $212-244$ & 48 & 5.0 & 0.583 & 0.777 & 0.195 & KY673702 \\
\hline HM02 & $(\mathrm{CT})_{25}$ & $\begin{array}{l}\text { F:ACAGAACACATCCAAACAAAGG } \\
\text { R:AACCAAAAGAAAGGAGCGAC }\end{array}$ & 51 & $207-254$ & 50 & 7.0 & 0.750 & 0.824 & 0.356 & KY673703 \\
\hline HM03 & $(\mathrm{GT})_{9}$ & $\begin{array}{l}\text { F:TGTCACACGCAGGGTAATG } \\
\text { R:TCAGGCAGCCGCAGTAT }\end{array}$ & 52 & $187-295$ & 50 & 8.0 & 0.733 & 0.769 & 0.399 & KY673704 \\
\hline HM04 & $(\mathrm{GA})_{15}$ & $\begin{array}{l}\text { F:AAGACGGTATGCCAGGGTT } \\
\text { R:GTTCAGGAGCAAAAAAATAAGAGA }\end{array}$ & 51 & $228-306$ & 45 & 6.0 & 0.607 & 0.744 & 0.043 & KY673705 \\
\hline HM05 & $(\mathrm{AG})_{13}$ & $\begin{array}{l}\text { F:GAAGAAGTGAGAGAAAAGGGG } \\
\text { R:ATTATGTGAAAGTGCTGCGAG }\end{array}$ & 53 & $191-207$ & 50 & 7.0 & 0.733 & 0.757 & 0.014 & KY673706 \\
\hline HM06 & $(\mathrm{CT})_{10}$ & $\begin{array}{l}\text { F:CAAAGGTTAGCCCCAAATCTG } \\
\text { R:CGCACAATAAGCAATCACATAC }\end{array}$ & 55 & $201-219$ & 46 & 4.0 & 0.483 & 0.513 & 0.166 & KY673707 \\
\hline HM07 & $(\mathrm{CA})_{10}$ & $\begin{array}{l}\text { F:GCACACCTGACCGTGAACA } \\
\text { R:GAAGAGAACAACCTGGTAATGAACT }\end{array}$ & 54 & $180-217$ & 45 & 7.0 & 0.632 & 0.680 & 0.150 & KY673708 \\
\hline HM08 & $(\mathrm{GACA})_{23}$ & $\begin{array}{l}\text { F:AAATGTTTGGCTGTGCTATGA } \\
\text { R:ATTGTGTGGCTGTTTTGTGTTA }\end{array}$ & 51 & $236-306$ & 50 & 6.0 & 0.542 & 0.700 & 0.082 & KY673709 \\
\hline HM09 & $(\mathrm{TC})_{26}$ & $\begin{array}{l}\text { F:TGCCTTTTGGAAATCAGCCT } \\
\text { R:ACATCTCCCTAACAGTCGCATAATA }\end{array}$ & 51 & $262-303$ & 50 & 7.0 & 0.811 & 0.756 & 0.137 & KY673710 \\
\hline HM10 & $(\mathrm{AC})_{11}$ & $\begin{array}{l}\text { F:TCTTTGCTTTCTCTCGGTGA } \\
\text { R:GGATGTGGTTTTGGTGTGTC }\end{array}$ & 51 & $191-203$ & 49 & 5.0 & 0.608 & 0.693 & 0.028 & KY673711 \\
\hline HM11 & $(\mathrm{TG})_{10}$ & $\begin{array}{l}\text { F:GCTCTGATACACAGCAGGACAA } \\
\text { R:GGCAACACAAAAAAGGGG }\end{array}$ & 51 & $182-253$ & 50 & 6.0 & 0.533 & 0.672 & 0.818 & KY673712 \\
\hline HM12 & $(\mathrm{CA})_{17}$ & $\begin{array}{l}\text { F:ATGCCACCTCCTCCACAC } \\
\text { R:TCCCCAAAAACACCTCTCA }\end{array}$ & 54 & $226-295$ & 50 & 7.0 & 0.715 & 0.730 & 0.079 & KY673713 \\
\hline HM13 & $(\mathrm{GT})_{19}$ & $\begin{array}{l}\text { F:GAGGAGGACGGGGGGAGCAGAA } \\
\text { R:CCAGCCTAATGGCAACAAGGGAT }\end{array}$ & 55 & $280-392$ & 48 & 5.0 & 0.580 & 0.565 & 0.085 & KY673714 \\
\hline HM14 & $(\mathrm{CA})_{9}$ & $\begin{array}{l}\text { F:GCCCTCATTGACTGCTATCTGCT } \\
\text { R:CCATTACAGTTTTAGCCTGAGCGT }\end{array}$ & 55 & $181-272$ & 50 & 10.0 & 0.825 & 0.840 & 0.102 & KY673715 \\
\hline HM15 & $(\mathrm{GT})_{9}$ & $\begin{array}{l}\text { F:GTGAAGAGAACAACCTGGTAATG } \\
\text { R:GCACACCTGACCGTGAACA }\end{array}$ & 53 & $186-298$ & 50 & 7.0 & 0.617 & 0.795 & 0.001 & KY673716 \\
\hline HM16 & $(\mathrm{GT})_{11}$ & $\begin{array}{l}\text { F:TTGTCTGACTGTCTGTGCTTTTGTT } \\
\text { R:GTTGACTAATGCGATGCTGGTTC }\end{array}$ & 54 & $201-262$ & 50 & 9.0 & 0.833 & 0.840 & 0.926 & KY673717 \\
\hline
\end{tabular}

$\mathrm{Ta}$ - specific annealing temperature; $\mathrm{Na}$ - number of alleles; $\mathrm{Ho}$ - observed heterozygosity; $\mathrm{He}$ - expected heterozygosity; $P_{\mathrm{HW}}$ - probability of departure from Hardy - Weinberg equilibrium

\section{Acknowledgements}

This work was supported by the Research Project of Zhejiang Province of China (No. 2016F30023).

\section{References}

Choi, E. Y., Hwang, H. J., Kim, I. H. and Nam, T. J. 2009. Protective effects of a polysaccharide from Hizikia fusiformis against ethanol toxicity in rats. Food Chem. Toxicol., 47: 134-139.

Fischer, D. and Bachmann, K. 1998. Microsatellite enrichment in organisms with large genomes (Allium cepa L.). Biotechniques, 24: 796-802.

Hwang, E. K., Park, C. S. and Sohn, C. H. 1994. Effects of light intensity and temperature on regeneration, differentiation and receptacle formation of Hizikia fusiformis (Harvey) Okamura. Korean J. Phycol., 9: 85-94.

Liu, F., Wang, F. and Duan, D. 2012. EST-SSR markers derived from Laminaria digitata and its transferable application in Saccharina japonica. J. Appl. Phycol., 24(3): 501-505.
Nan, C. R., Zhang, P., Lin, S. Z., Wu, C. Y. and Zhang, L. 2015. ISSR analysis of genetic variation of Hizikia fusiformis wild and breeding strains in Wenzhou. Acta Agriculturae Zhejiangensis, 27: 234-239. (In Chinese with English abstract)

Park, J. W., Cho, Y. C., Nam, B. H., Jin, H. J., Sohn, C. H. and Hong, Y. K. 1998. RAPD identification of genetic variation in seaweed Hizikia fusiformis (Fucales, Phaeophyta). J. Mar. Biotechnol., 6: 62-64.

Pang, S. J., Chen, L. T., Zhuang, D. G., Fei, X. G. and Sun, J. Z. 2005. Cultivation of the brown alga Hizikia fusiformis (Harvey) Okamura: enhanced seedling production in tumbled culture. Aquaculture, 245: 321-329.

Pang, S. J., Gao, S. Q. and Sun., J. Z. 2006. Cultivation of the brown alga Hizikia fusiformis (Harvey) Okamura: controlled fertilisation and early development of seedlings in raceway tanks in ambient light and temperature. J. Appl. Phycol., 18: 723-731.

Peakall, R. O. D. and Smouse, P. E. 2006. GENALEX 6: genetic analysis in Excel. Population genetic software for teaching and research. Mol. Ecol. Notes, 6: 288-295. 
Rice, W. 1989. Analysing tables of statistical tests. Evolution, 43: 223-225.

Rousset, F. 2008. GENEPOP'007: a complete re-implementation of the genepop software for Windows and Linux. Mol. Ecol. Resour., 8:103-106.

Rozen, S. and Skaletsky, H. 2000. Primer3 on the WWW for General Users and for Biologist Programmers. In Methods in molecular biology, Humana Press, Totowa, NJ, p. 365-386.

Sassenhagen, I. and Erdner, D. L. 2017. Microsatellite markers for the dinoflagellate Gambierdiscus caribaeus from high-throughput sequencing data. J. Appl. Phycol., 29: 1927-1932.

Shan, T. F. and Pang, S. J. 2009. Assessing genetic identity of sporophytic offspring of the brown alga Undaria pinnatifida derived from mono-crossing of gametophyte clones by use of amplified fragment length polymorphism and microsatellite markers. Phycol. Res., 57: 36-44.
Sun, J. Z., Fang, J. Z. and Zhu, Z. F. 1996. A preliminary study on the reproductive biology of Sargassum fursiforme. J. Zhejiang Coll. Fish., 15: 243-249 (in Chinese with English abstract).

Song, S. L., Lim, P. E., Phang, S. M., Lee, W. W., Hong, D. D. and Prathep, A. 2014. Development of chloroplast simple sequence repeats (cpSSRs) for the intraspecific study of Gracilaria tenuistipitata (Gracilariales, Rhodophyta) from different populations. BMC Res. Notes, 7: 77.

Yu, S., Deng, Y., Yao, J., Li, S., Xin, X. and Duan, D. 2012. Population genetics of wild Hizikia fusiformis (Sargassaceae, Phaeophyta) along China's coast. J. Appl. Phycol., 24: 1287-1294.

Yue, G. H., Chen, F. and Orban, L. 2000. Rapid isolation and characterisation of microsatellites from the genome of Asian arowana (Scleropages formosus, Osteoglossidae, Pisces). Mol. Ecol., 9: 1007-1009. 